\title{
АНАЛИЗ ЛЕСНЫХ ПОЖАРОВ ПО МНОГОЛЕТНИМ СТАТИСТИЧЕСКИМ ДАННЫМ
}

\section{П.М. Мазуркин}

\begin{abstract}
Шкалу времени регистрации лесных пожаров в прошлом измеряют в сутках, за нулевое значение времени регистрации принимают момент первого зарегистрированного в книге учета лесного пожара. Из книги учета принимают первичные показатели о лесных пожарах, выполняют корректировку статистических данных относительно принятой шкаль времени регистрации лесных пожаров, дополнительно учитыввют производные от первичных показателей. Приведены статистические модели каждого первичного и производного от него показателя в зависимости от времени регистрации лесных пожаров. Кратко изложен метод идентификации волновых функиий в виде асимметричных вейвлет-сигналов.
\end{abstract}

Ключевые слова: лесные пожары, показатели, измерение, динамика, закономерности, вейвлет-сигнальл.

Введение. Совокупность лесных пожаров принимается за динамическую популяцию, поведение которой изменяется во времени регистрации лесных пожаров на одной и той же территории.

Время регистрации лесных пожаров измеряется физической единицей (в сутках) как цикл вращения Земли вокруг своей оси. Результаты измерений времени регистрации лесных пожаров принимаются как влияющая переменная для всех первичных (измеренных) и производных из первичных (расчетных) показателей лесных пожаров.

При этом время обнаружения и окончания тушения, а также разность между ними как период лесного пожара из обычной системы исчисления времени (часы, минуты и секунды) преобразуются в десятичную систему счисления (в часах и десятичных долях часа).

Положительный эффект достигается тем, что повышаются функциональные возможности системы типа «Лесной Дозор», а также точность инерционного прогнозирования лесных пожаров, в её программной части - это специальное программное обеспечение, с помощью которого заказчик осуществляет мониторинг лесов в режиме реального времени с момента регистрации первого на данной территории лесного пожара и определяет количество возгораний на одной и той же координате.

Новизна метода анализа [1-12] заключается в том, что впервые выполнено преобразование пассивной статистической выборки из книги учета

\section{Мазуркин Петр Матвеевич,}

доктор технических наук, профессор,

Поволжский ГТУ,

e-mail: kaf_po@mail.ru

(C) Мазуркин П.М., 2014 лесных пожаров в динамическую систему поведения локальной лесной точки на земной поверхности в зависимости от времени регистрации лесных пожаров, определяемых по датам и времени регистрации. В итоге материальный объект в виде Земли (суточные циклы) воздействует на популяцию лесных пожаров, то есть на лесной ландшафт на конкретной территории. В связи с этим суточное время регистрации лесных пожаров становится влияющей физической переменной, позволяющей в дальнейшем увязать параметры различных природных явлений (освещенности, тепловой радиации, метеорологических показателей и пр.) с параметрами каждого единичного лесного пожара - периодом и площадью пожара, его средней скоростью.

Регистрация пожаров. Государственный природный Национальный парк «Марий Чодра» (в переводе «марийский лес») организован 1 декабря 1985 года. Название его не случайно - вся территория парка покрыта прекрасными сосновыми борами и хвойно-широколиственными лесами. Парк находится на юго-востоке Республики Марий Эл, в трех административных районах - Моркинском, Звениговском, Волжском - в 20-40 километрах от г. Волжска и 50-70 километрах от г. Йошкар-Олы.

Книга учета лесных пожаров ФГБУ «Национальный парк «Марий Чодра» представляет собой журнал, в котором составитель акта о пожаре (старший инженер ОЗЛ, начальник ПХС, лесничий, помощник лесничего, мастер леса) лесничества, где произошло возгорание, записывает все известные ему данные о возгорании.

Данная Книга учета лесных пожаров ведется в НП «Марий Чодра» с 1982 г. (Табл. 1). 
Данные по лесным пожарам за 1982-2011 гг.

\begin{tabular}{|c|c|c|c|c|c|c|}
\hline \multirow[b]{2}{*}{ Дата } & \multicolumn{3}{|c|}{ Моменты времени, ч : мин } & \multirow[b]{2}{*}{ Лесничество } & \multirow[b]{2}{*}{ Квартал } & \multirow{2}{*}{$\begin{array}{c}\begin{array}{c}\text { Площадь } \\
\text { лесная } \\
\text { (га) }\end{array} \\
\end{array}$} \\
\hline & $\begin{array}{c}\text { Обнаружение } \\
\text { пожара }\end{array}$ & $\begin{array}{l}\text { Начало } \\
\text { тушения }\end{array}$ & \begin{tabular}{|c|} 
Окончание \\
тушения
\end{tabular} & & & \\
\hline 01.08 .1982 & $19: 35$ & $20: 05$ & $5: 20$ & Яльчинское & 84 & 0,6 \\
\hline 16.08 .1982 & $16: 50$ & - & $8: 30$ & Лушмарское & 61 & 0 \\
\hline 27.08 .1982 & $14: 55$ & 18:00 & 19:00 & Кленовогорское & 54 & 0,03 \\
\hline 30.08 .1982 & $15: 50$ & $16: 00$ & $14: 00$ & Лушмарское & 24 & 0,02 \\
\hline 30.08 .1982 & 18:00 & $18: 40$ & $22: 00$ & Кленовогорское & 26 & 0,02 \\
\hline 02.09 .1982 & $16: 50$ & $17: 00$ & $20: 00$ & Яльчинское & 80 & 0,02 \\
\hline 15.05 .1983 & $16: 00$ & $16: 30$ & 21:00 & Яльчинское & 86 & 2 \\
\hline 30.05 .1983 & $14: 40$ & $15: 10$ & 19:00 & Яльчинское & 34 & 0,03 \\
\hline$\ldots$ & $\ldots$ & $\ldots$ & $\ldots$ & $\ldots$ & $\ldots$ & $\ldots$ \\
\hline 23.05 .2011 & $16: 10$ & $16: 10$ & $17: 30$ & Кленовогорское & 27 & 0,001 \\
\hline 26.07 .2011 & $9: 30$ & $9: 30$ & $14: 00$ & Яльчинское & 32 & 0,01 \\
\hline 07.08 .2011 & $17: 30$ & $17: 30$ & 19:00 & Яльчинское & 59 & 0,01 \\
\hline 13.08 .2011 & $20: 00$ & $20: 15$ & 12:00 14.08 & Кленовогорское & 26 & 0,015 \\
\hline
\end{tabular}

Исходные данные для статистического моделирования. По данным Книги учета лесных пожаров дополнительно были определены следующие показатели для моделирования (Табл. 2):

1) время с начала регистрации (сутки), при этом для первой регистрация пожара 01.08.1982 время с начала регистрации равно нулю;

2) годы текущего времени (лет);

3) время по пожароопасному сезону (сутки);

4) промежуток между пожарами по времени обнаружения (сутки).

Промежуток времени между пожарами по времени их обнаружения рассчитывается следующим образом: из даты последующего пожара вычи- тается дата предыдущего. С учетом високосного года учитывается промежуток времени после последнего пожара в данном году до первого пожара в следующем календарном году. Выглядит это так: 16.08.1982 - 01.08.1982=15 суток.

Время с начала регистрации (сутки) рассчитывается за все годы вместе, причем как кумулята:

$0+15=15 ; 15+11=26 ; 26+3=29 ; 29+0=$ $29 ; 29+3=32$ и т.д.

Годы текущего времени получаются, начиная с нуля для первого года. Время по сезону года (сутки) рассчитывается аналогично как время с начала регистрации только отдельно по годам.

Таблица 2

Динамика лесных пожаров в «Марий Чодра» за 1982-2011 гг.

\begin{tabular}{|c|c|c|c|c|c|c|c|}
\hline \multirow[b]{2}{*}{$\begin{array}{c}\text { № } \\
\text { ПI/II }\end{array}$} & \multirow[b]{2}{*}{$\begin{array}{c}\text { Дата } \\
\text { регистрации } \\
\text { лесного } \\
\text { пожара }\end{array}$} & \multirow[b]{2}{*}{$\begin{array}{c}\text { Время } \\
\text { между } \\
\text { пожарами, } \\
\text { сутки }\end{array}$} & \multirow{2}{*}{$\begin{array}{c}\text { Время } \\
\text { с начала } \\
\text { регистра- } \\
\text { ции, } \\
\text { сутки }\end{array}$} & \multicolumn{3}{|c|}{ Параметры пожара, ч } & \multirow[b]{2}{*}{$\begin{array}{c}\text { Площадь } \\
\text { лесного } \\
\text { пожара, } \\
\text { га }\end{array}$} \\
\hline & & & & $\begin{array}{c}\text { Время } \\
\text { обнару- } \\
\text { жения }\end{array}$ & $\begin{array}{c}\text { Начало } \\
\text { тушения }\end{array}$ & $\begin{array}{c}\text { Окон- } \\
\text { чание } \\
\text { тушения }\end{array}$ & \\
\hline 1 & 01.08 .1982 & 0 & 0 & 19,58 & 20,08 & 5,33 & 0,6 \\
\hline 2 & 16.08 .1982 & 15 & 15 & 16,83 & - & 8,50 & - \\
\hline 3 & 27.08 .1982 & 11 & 26 & 14,92 & 18,00 & 19,00 & 0,03 \\
\hline 4 & 30.08 .1982 & 3 & 29 & 15,83 & 16,00 & 14,00 & 0,02 \\
\hline 5 & 30.08 .1982 & 0 & 29 & 18,00 & 18,67 & 22,00 & 0,02 \\
\hline 6 & 02.09 .1982 & 3 & 32 & 16,83 & 17,00 & 20,00 & 0,02 \\
\hline 7 & 15.05 .1983 & 256 & 287 & 16,00 & 16,50 & 21,00 & 2 \\
\hline 8 & 30.05 .1983 & 15 & 302 & 14,67 & 15,17 & 19,00 & 0,01 \\
\hline$\ldots$ & $\ldots$ & $\ldots$ & $\ldots$ & $\ldots$ & $\ldots$ & $\ldots$ & $\ldots$ \\
\hline 257 & 23.05 .2011 & 253 & 10584 & 16,17 & 16,17 & 17,5 & 0,001 \\
\hline 258 & 26.07 .2011 & 64 & 10648 & 9,5 & 9,5 & 14 & 0,01 \\
\hline 259 & 07.08 .2011 & 12 & 10660 & 17,5 & 17,5 & 19 & 0,01 \\
\hline 260 & 13.08 .2011 & 6 & 10666 & 20 & 20,25 & - & 0,015 \\
\hline
\end{tabular}


Остальные четыре параметра лесного пожара, приведенные в Табл. 2, получаются из данных таблицы 1 при переводе минут в десятичные доли часа. Всего в книге учета за период 1982-2011 гг. оказалось 260 лесных пожаров.

Для технического решения были отобраны шкалы времени (Табл. 3): $t$ - время с начала регистрации, сутки; $t_{2}$ - годы текущего времени, лет.

Время обнаружения и окончания тушения сами по себе не имеют факторного значения, но вычитанием дают продолжительность, или период лесного пожара $-T$. Основным физическим параметром для измерения потушенного лесного пожара является фактор - площадь лесного пожара (территория, пройденная пожаром) $S$.

Взаимные отношения между параметрами $T$ и $S$ дают еще два показателя (они в данном техническом решении не учитываются): $s_{T}=S / T$ - средняя скорость каждого лесного пожара, ${ }^{2} / \mathrm{c}$; $\tau_{S}=T / S$ - удельное время каждого лесного пожара, $\mathrm{c} / \mathrm{M}^{2}$. Однако по шести строкам оказались прочерки в массиве данных по площади пожара, поэтому остались 254 строки в таблице 3 за 30 лет.

Таблица 3

Динамика лесных пожаров в «Марий Чодра» за 1982-2009 гг.

\begin{tabular}{|c|c|c|c|c|c|r|r|}
\hline $\begin{array}{c}\text { № } \\
\text { п/п }\end{array}$ & $\begin{array}{c}\text { Время } \\
\text { реги- } \\
\text { страции } \\
t, \text { сутки }\end{array}$ & $\begin{array}{c}\text { Время } \\
\text { обнару- } \\
\text { жения }\end{array}$ & $\begin{array}{c}\text { Окон- } \\
\text { чание } \\
\text { туше- } \\
\text { ния }\end{array}$ & $\begin{array}{c}\text { Период } \\
\text { пожара } \\
T, \mathbf{ч}\end{array}$ & $\begin{array}{c}\text { Площадь } \\
\text { пожара } \\
S, \mathbf{r a}\end{array}$ & $\begin{array}{c}\text { Средняя } \\
\text { скорость } \\
\text { пожара } \\
s_{T}, \mathbf{2} / \mathbf{c}\end{array}$ & $\begin{array}{c}\text { Удельное } \\
\text { время } \\
\text { тушения } \\
\tau_{S}, \mathbf{c} / \mathbf{m}^{2}\end{array}$ \\
\hline 1 & 0 & 19.58 & 5.33 & 9.75 & 0.6 & 0.1709 & 5.85 \\
\hline 2 & 26 & 14.92 & 19.00 & 4.08 & 0.03 & 0.0204 & 48.96 \\
\hline 3 & 29 & 14.00 & 15.83 & 1.83 & 0.02 & 0.0304 & 32.94 \\
\hline 4 & 29 & 18.00 & 22.00 & 4 & 0.02 & 0.0139 & 72.00 \\
\hline 5 & 32 & 16.83 & 20.00 & 3.17 & 0.02 & 0.0175 & 57.06 \\
\hline & $\ldots$ & $\ldots$ & $\ldots$ & $\ldots$ & $\ldots$ & $\ldots$ & $\ldots$ \\
\hline 250 & 10288 & 12,25 & 13,083 & 0.833 & 0.0075 & 0.0250 & 39.98 \\
\hline 251 & 10331 & 18,083 & 19,5 & 1.417 & 0.005 & 0.0098 & 102.02 \\
\hline 252 & 10584 & 16,17 & 17,5 & 1.33 & 0.001 & 0.0021 & 478.80 \\
\hline 253 & 10648 & 9,5 & 14 & 4.5 & 0.01 & 0.0062 & 162.00 \\
\hline 254 & 10660 & 17,5 & 19 & 1.5 & 0.01 & 0.0185 & 54.00 \\
\hline
\end{tabular}

Структурная идентификация. Декарт предполагал существование одного-единственного алгебраического уравнения, пригодного как вариант решения для любых типов интегральных уравнений.
Гильберт мечтал об инвариантах, из которых как из кирпичиков будет собираться это универсальное уравнение.

Универсальные инварианты даны в Табл. 4.

\section{Математические конструкты (исходные инварианты) для моделирования методом идентификации}

\begin{tabular}{|c|c|}
\hline $\begin{array}{c}\text { Фрагменты без предыстории } \\
\text { изучаемого явления } \\
\text { или процесса }\end{array}$ & $\begin{array}{c}\text { Фрагменты с предысторией } \\
\text { изучаемого явления } \\
\text { или процесса }\end{array}$ \\
\hline $\begin{array}{l}y=a x-\text { закон линейного роста или спада (при } \\
\text { отрицательном знаке перед правой стороной } \\
\text { формулы линейного изменения) }\end{array}$ & $\begin{array}{l}y=a-\text { закон невлияния принятой объясняющей } \\
\text { переменной на показатель, который имеет собст- } \\
\text { венную предысторию значений }\end{array}$ \\
\hline $\begin{array}{l}y=a x^{b}-\text { закон показательного роста (закон } \\
\text { показательной гибели } y=a x^{-b} \text { не является ус- } \\
\text { тойчивым, из-за бесконечности показателя при } \\
\text { нулевом значении объясняющей переменной) }\end{array}$ & $\begin{array}{l}y=a \exp ( \pm c x)-\text { закон Лапласа в математике } \\
\text { (Ципфа в биологии, Парето в экономике, Ман- } \\
\text { дельброта в физике) экспоненциального роста } \\
\text { или гибели, относительно которого Лаплас создал } \\
\text { операторное исчисление }\end{array}$ \\
\hline $\begin{array}{l}y=a x^{b} \exp (-c x)-\text { биотехнический закон в уп- } \\
\text { рощенной форме (П.М. Мазуркин), когда пока- } \\
\text { зательный рост постепенно получает экспонен- } \\
\text { циальное торможение }\end{array}$ & $\begin{array}{l}y=a \exp \left( \pm c x^{d}\right)-\text { закон экспоненциального роста } \\
\text { или гибели в полной форме (конструкции), кото- } \\
\text { рый имеет интенсивность, не равную единице } \\
\text { (П.М. Мазуркин) }\end{array}$ \\
\hline$y=a x^{b} \exp \left(-c x^{d}\right)-$ биотехнический закон, общиі & для шести конструктов (П.М. Мазуркин) \\
\hline
\end{tabular}


Они сгруппированы по принципу «от простого к сложному». По сути фрагменты и сам биотехнический закон являются «кирпичиками Гильберта» для построения, в ходе процесса структурнопараметрической идентификации, аддитивной конструкции искомой статистической детерминированной или волновой модели. Инварианты колебательных возмущений в виде асимметричных вейвлетсигналов также включают в себя конструкты из Табл. 4 как амплитуда (половина) и полупериод.

В Табл. 4 показаны все наиболее встречающиеся инварианты (фрагменты). У них впереди могут быть расположены оперативные константы «+» или «-». Шесть устойчивых законов распределения являются частными случаями биотехнического закона, показанного внизу Табл. 4. В названии закона слово «биотехнический» означает, что мы придерживаемся идей В.И. Вернадского о космической функции жизни.

Если известна эвристическая предыстория формирования числового поля (табличной модели), то вполне возможна смысловая расшифровка каждого вейвлет-сигнала, у которого вейвлет (волновая функция) в своей конструкции содержит те или иные математические инварианты из Табл. 4.

Устойчивые законы и закономерности на их основе делают выбор уравнения для последующей идентификации на статистических данных (числовых полях) вполне осмысленным, и поэтому вероятностное моделирование остается только при случайном поиске программной средой типа CurveExpert значений параметров у искомой моде- ли. Поэтому из теории идентификации первый этап (выбор случайной структуры уравнения) исключается и остается только второй этап - случайная идентификация значений параметров искомой модели.

Идентификация структуры модели проводится обработкой исходных данных следующим образом:

- вначале выявить детерминированные нелинейные закономерности;

- затем дополнять эти трендовые закономерности колебательными возмущениями.

Идентификация параметрическая. Она выполнялась в программной среде CurveExpert-1.38 или CurveExpert-1.40 (Программная среда CurveExpert. - URL : http://www.curveexpert.net/) и информационной технологией идентификации пользуются студенты (будущие бакалавры и магистры), а также аспиранты и докторанты.

Выбор структуры искомой модели, которая является алгебраическим решением по Декарту для неизвестной первообразной по волновым уравнениям, имеющим переменные амплитуду и полупериод (половины частоты как обратная величина полупериода) колебательного возмущения объекта исследования, выполняется из устойчивых законов (инвариантов), приведенных в Табл. 4.

Уровни адекватности выявляемых закономерностей. В Табл. 5 приведены интервалы изменения коэффициента корреляции как меры адекватности модели.

\section{Уровни тесноты факторных связей}

\begin{tabular}{|c|c|c|c|}
\hline \multirow{2}{*}{$\begin{array}{c}\text { Интервал } \\
\text { коэффициента } \\
\text { корреляции }\end{array}$} & \multicolumn{3}{|c|}{ Характер тесноты связи между факторами } \\
\hline & $\begin{array}{l}\text { существующая } \\
\text { классификация }\end{array}$ & $\begin{array}{c}\text { шкала для } \\
\text { технических } \\
\text { измерений }\end{array}$ & $\begin{array}{c}\text { шкала для } \\
\text { прецизионных } \\
\text { измерений }\end{array}$ \\
\hline 1 & \multirow{5}{*}{ сильная связь } & однозначная & однозначная \\
\hline $0,99 \ldots 1,00$ & & \multirow{3}{*}{ сильнейшая } & $\begin{array}{l}\text { почти } \\
\text { однозначная }\end{array}$ \\
\hline $0,95 \ldots 0,99$ & & & сверхсильная \\
\hline $0,90 \ldots 0,95$ & & & сильнейшая \\
\hline $0,7 \ldots 0,9$ & & сильная & сильная \\
\hline $0,5 \ldots 0,7$ & \multirow{2}{*}{ слабая связь } & средняя & средняя \\
\hline $0,3 \ldots 0,5$ & & слабоватая & слабоватая \\
\hline $0,1 \ldots 0,3$ & \multirow{3}{*}{ нет связи } & слабая & слабая \\
\hline $0,0 \ldots 0,1$ & & слабейшая & слабейшая \\
\hline 0 & & нет связи & нет связи \\
\hline
\end{tabular}

Существующая шкала квантификации тесноты связи между принятыми факторами (нет связи, слабая и сильная связь) является очень грубой.

Влияние времени в сутках. Именно физический параметр - цикл обращения Земли вокруг своей оси, то есть сутки, стал основным влияющим параметром в процессе физико-математического анализа. Введение шкалы времени в сутках значительно изменило поведение популяции лесных пожаров за 30 лет на территории национального парка.

При этом первые три составляющие (Рис. 1) оказались примерно с такой же адекватностью. как это было для формулы (1). при коэффициенте корреляции 0.4019. Но применение единицы измерения времени регистрации в сутках позволила дать большое множество волновых членов уравнения. 


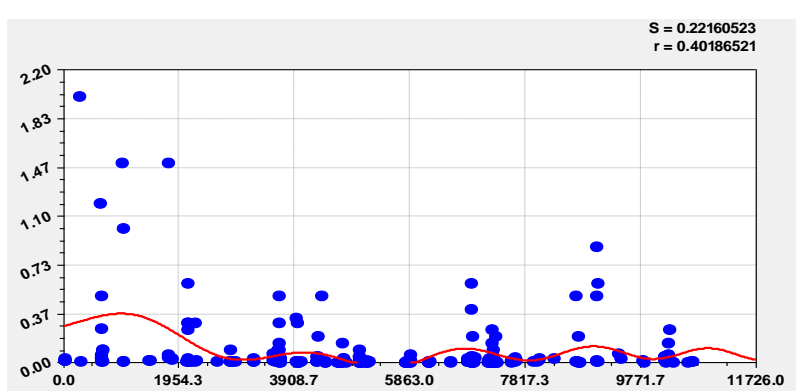

Рис. 1. График изменения площади лесного пожара от времени измерения в сутках

Асимметричный вейвлет. Мы придерживаемся концепции Декарта о необходимости применения алгебраического уравнения общего вида напрямую как конечного математического решения неизвестных интегральных уравнений.

Условиям существования наиболее полно удовлетворяет асимметричная вейвлет-функция

$$
\begin{aligned}
y= & \sum_{i=1}^{m} y_{i}, y_{i}=a_{1 i} x^{a_{2 i}} \exp \left(-a_{3 i} x^{a_{4 i}}\right) \times \\
& \times \cos \left(\pi x /\left(a_{5 i}+a_{6 i} x^{a_{7 i}}\right)-a_{8 i}\right),
\end{aligned}
$$

где $y$ - показатель (зависимый фактор), в нашем примере площадь лесного пожара, га, $i$ - номер составляющей модели (2), $m$ - количество членов в модели (2), $x$ - объясняющая переменная (влияющий фактор), $a_{1} . a_{10}$ - параметры, принимающие

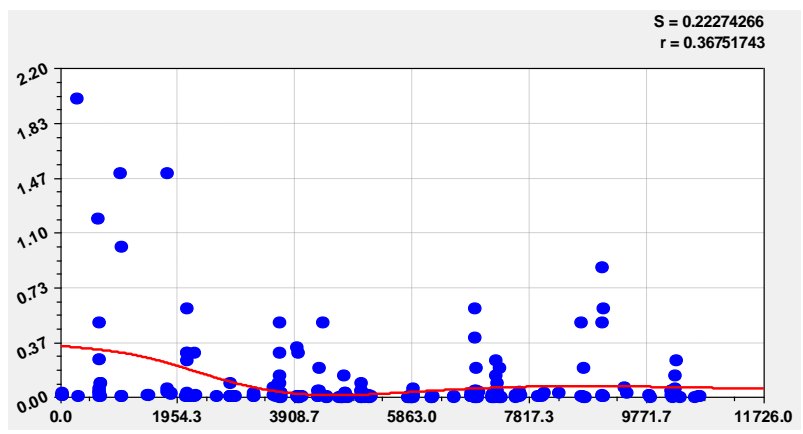

Тренд

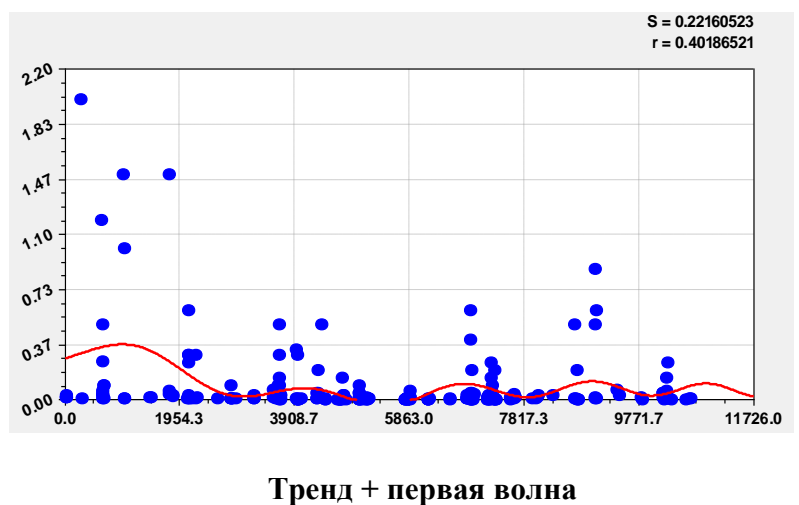

числовые значения в ходе структурнопараметрической идентификации (2).

Динамический ряд как череда сигналов. Физико-математический подход предполагает понимание смысла динамического ряда как отражения какого-то составного реального процесса.

Впервые удалось получить модели многих типов рядов динамики на концепции аддитивного разложения любого динамического ряда на множество сигналов. Понятие вейвлет-сигнала позволяет абстрагироваться от физического смысла самих рядов (в общем случае не только динамических) и рассматривать их аддитивное разложение.

На Рис. 2-5 показаны графики физикоматематического анализа динамики лесных пожаров за 1982-2011 гг. в «Марий Чодра».

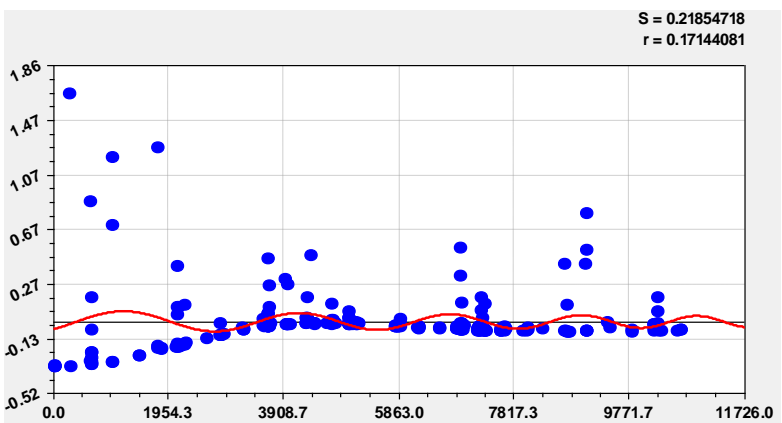

Первое колебание

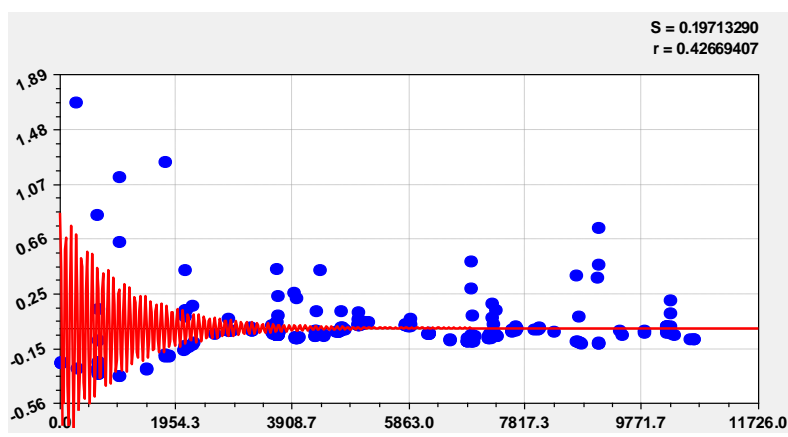

Второе колебательное возмущение 


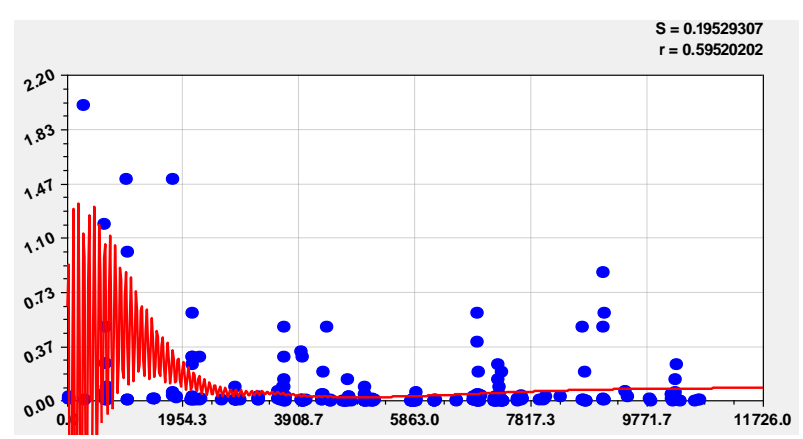

Тренд + две волны

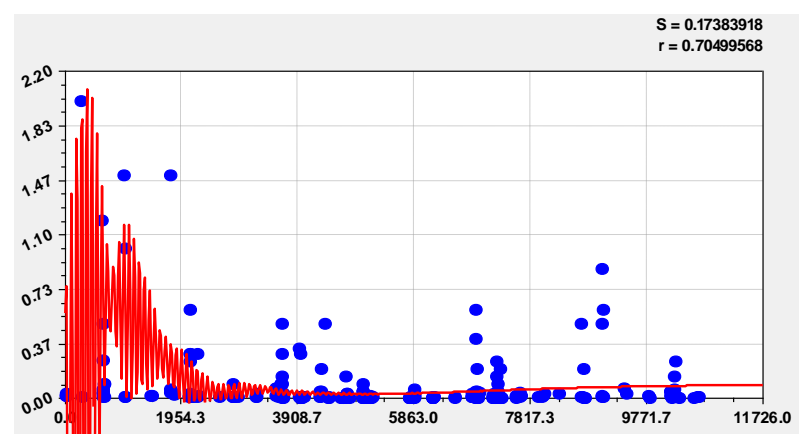

Тренд + три волны

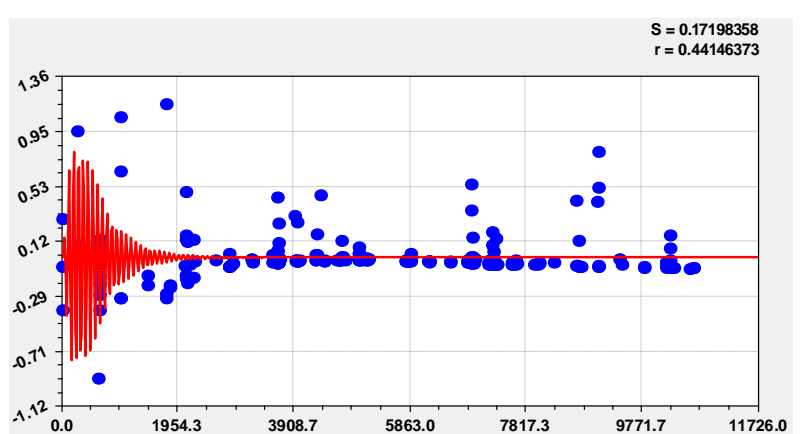

Третье колебательное возмущение

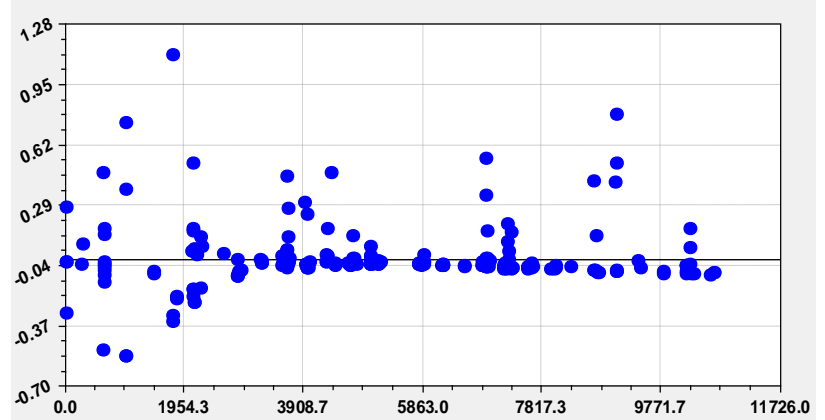

Остатки после «тренд + три волны»

Рис. 2. Графики тенденции трехволновых колебательных возмущений и их совместная динамика значений площади лесных пожаров за период 1982-2011 гг., полученные по возможностям программной среды CurveExpert-1.40

Сигнал - это материальный носитель информации. А информация нами понимается как мера взаимодействия. Сигнал может генерироваться, но его приём не обязателен. Так, например, ряд простых чисел известен несколько тысяч лет, но суть его как множества сигналов до сих пор не была раскрыта. Сигналом может быть любой физический процесс или его часть.

Получается, что изменение множества неизвестных сигналов давно известно, например, через ряды гидрометеорологических и иных климатических [3] измерений во многих точках планеты.

Тогда любое уравнение типа (2) можем записать как асимметричный вейвлет

$$
y_{i}=A_{i} \cos \left(\pi x / p_{i}-a_{8 i}\right)
$$

$$
\begin{gathered}
A_{i}=a_{1 i} x^{a_{2 i}} \exp \left(-a_{3 i} x^{a_{4 i}}\right) \\
, p_{i}=a_{5 i}+a_{6 i} x^{a_{7 i}} .
\end{gathered}
$$

где $A_{i}$ - амплитуда (половина) вейвлета (ось $y$ ). $p_{i}$ - полупериод колебания (ось $x$ ).

По формуле (3) с двумя фундаментальными физическими постоянными $е$ (число Непера или число времени) и $\pi$ (число Архимеда или число пространства) образуется изнутри изучаемого явления и/или процесса квантованный вейвлет-сигнал. Понятие вейвлет-сигнала позволяет абстрагироваться от физического смысла самих рядов (в общем случае не только динамических) и рассматривать их аддитивное разложение.
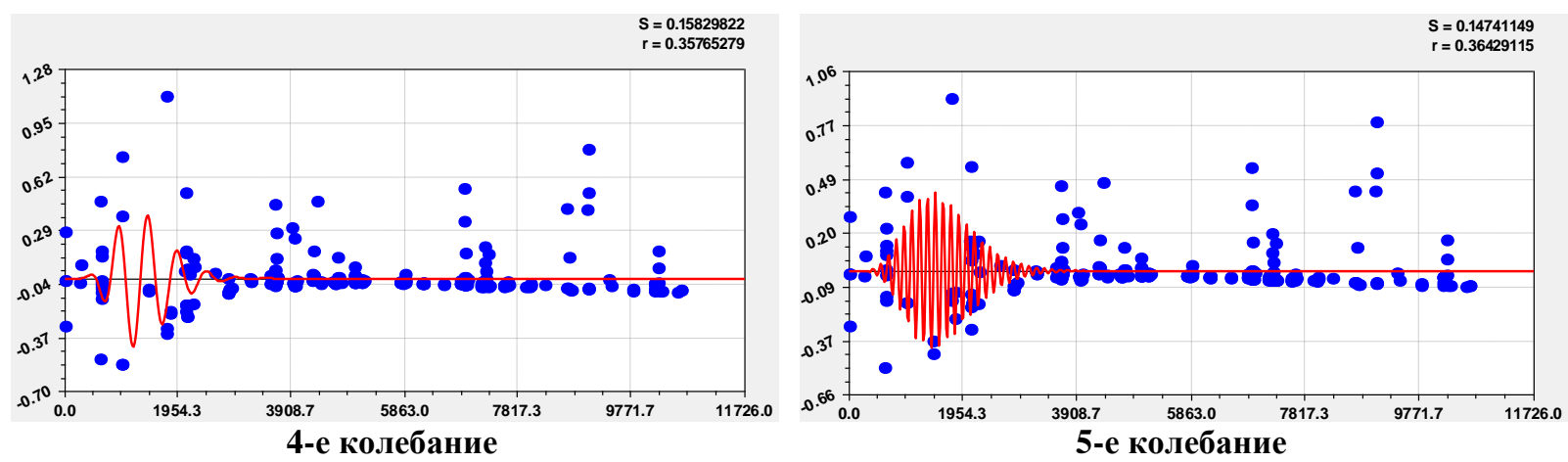

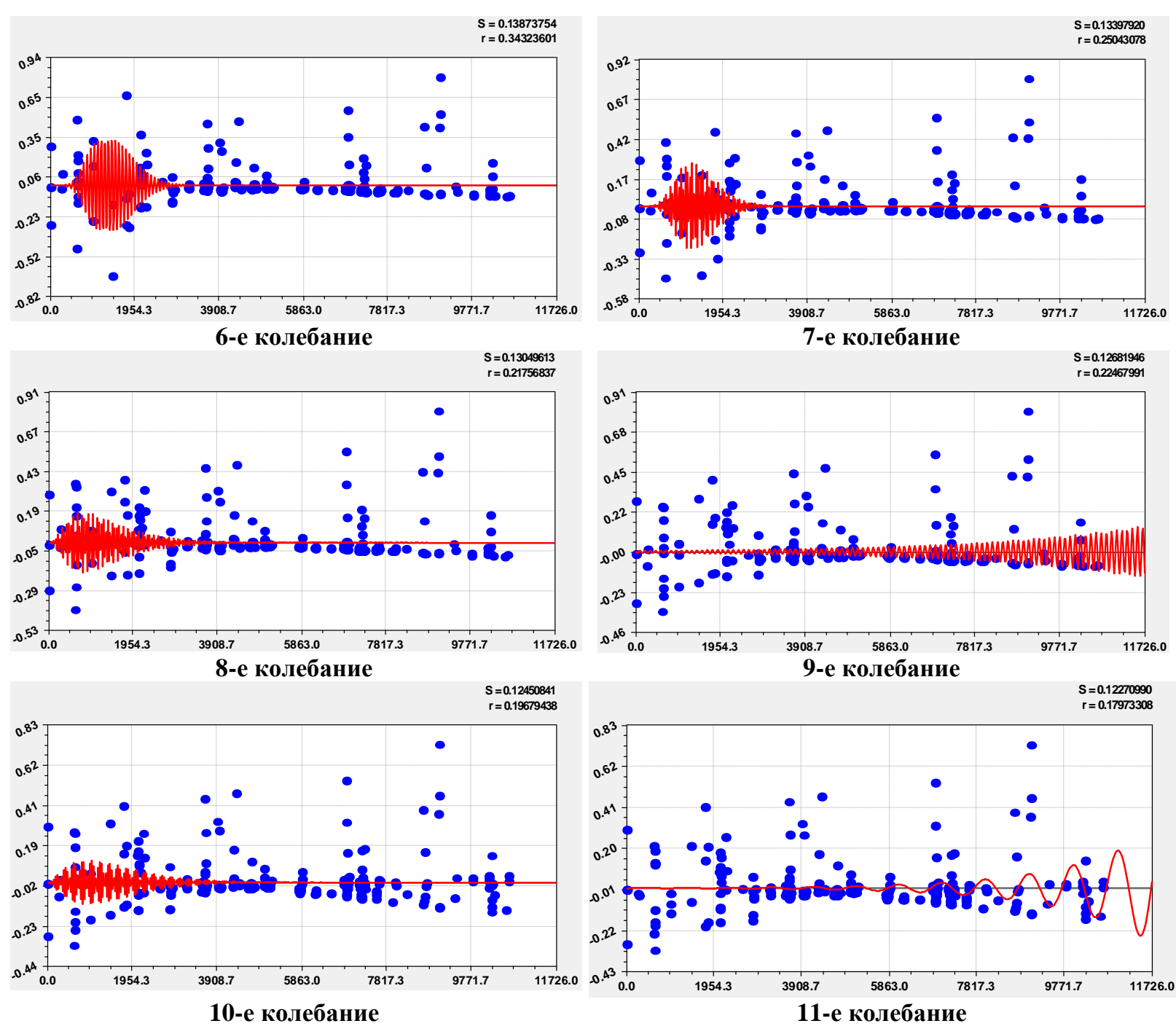

Рис. 3. Графики отдельных волновых уравнений (асимметричные вейвлет-сигналы) по второй части составляющих общей статистической модели динамики площади лесных пожаров в зависимости от времени измерения в сутках за период 1982-2011 гг.

Для краткой записи значений параметров уравнений всех 22 членов обобщенной функции (3) применена матричная форма (Табл. 6).

Остатки (Рис. 6) после 22-го члена (20-й волны колебательного возмущения) получили пару противоположно ориентированных значений при одной и той же абсциссе.

Как видно из точечного распределения, разброс точек возрастает до этой пары (показаны стрелками), а затем по инерции разброс повышается. Но в конце периода измерений точность измерений повышается (разброс резко уменьшается).

Заключение. Предлагаемый метод анализа обладает простотой проведения.
Причем по выявленным закономерностям можно было бы выполнить ориентировочный инерционный прогноз на горизонт прогноза, равный основанию прогноза (промежутку времени от нуля до последнего измерения лесного пожара), а также рабочий инерционный прогноз на одну треть периода прошлых измерений лесных пожаров. В итоге повышается оперативность тушения пожаров.

Применение предложенного метода расширяет возможности территориального экологического мониторинга, повышает функциональные возможности системы типа «Лесной Дозор». 


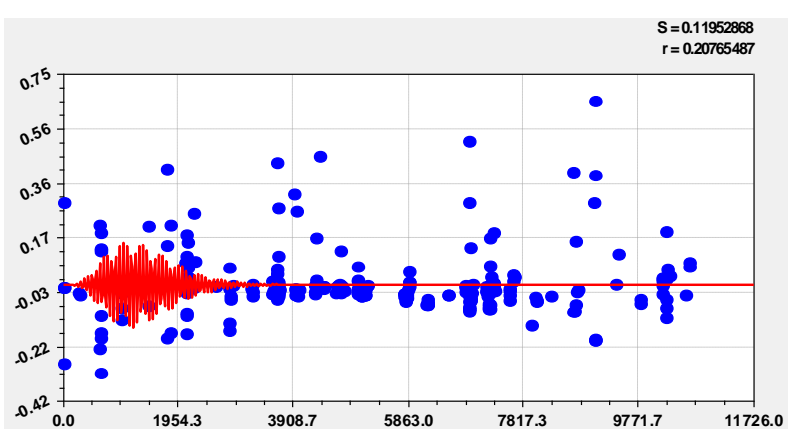

12-е колебание

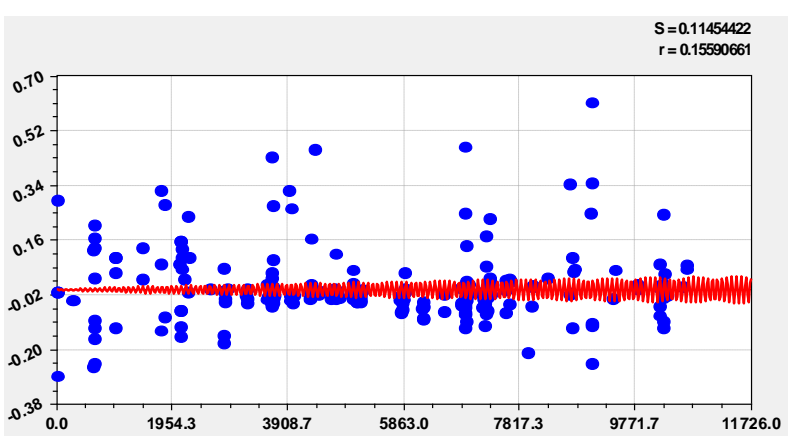

14-е колебание

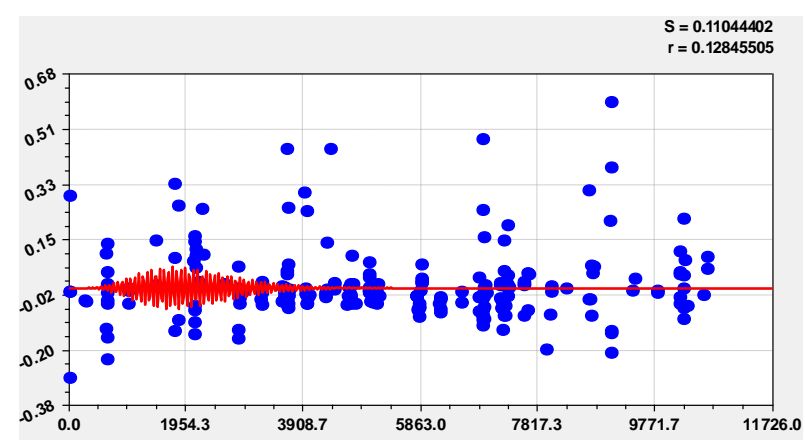

16-е колебание

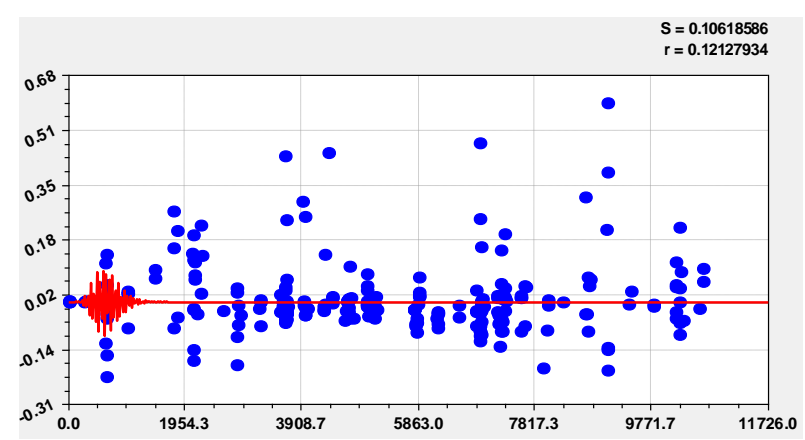

18-е колебание

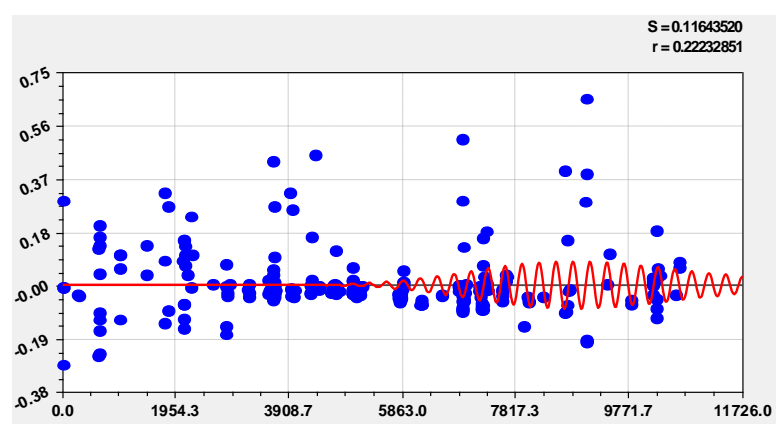

13-е колебание

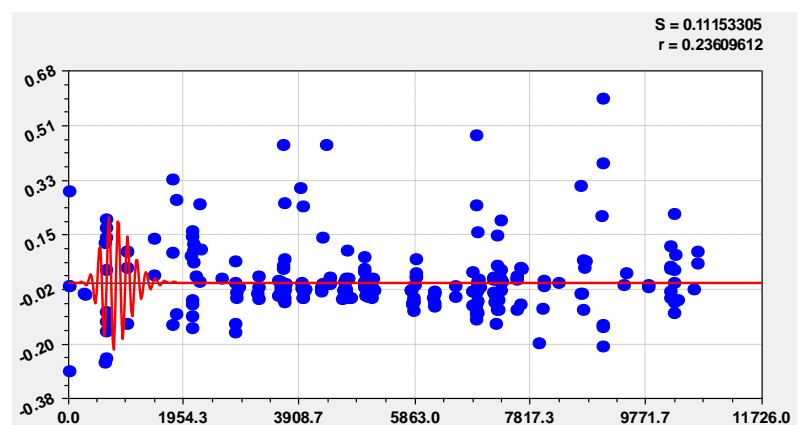

15-е колебание

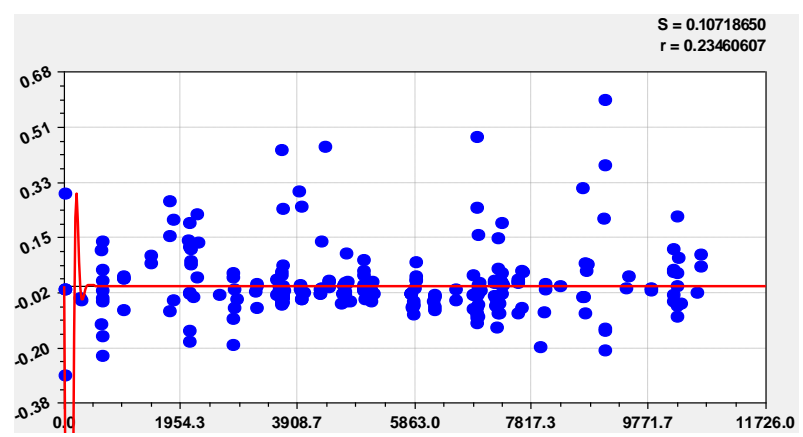

17-е колебание

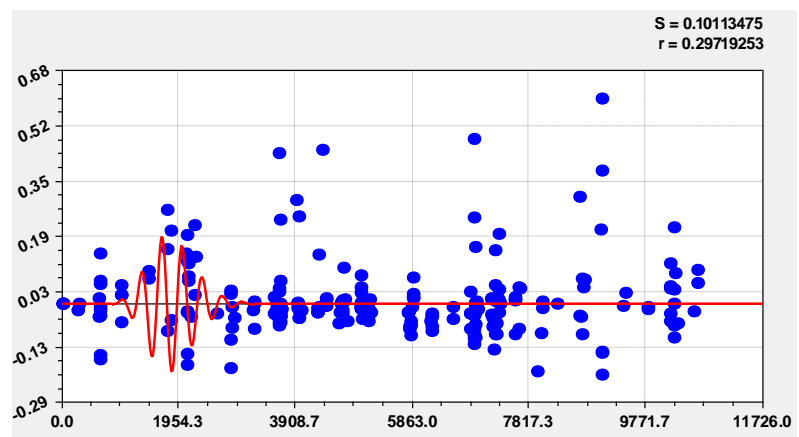

19-е колебание

Рис. 4. Графики отдельных волновых уравнений (асимметричные вейвлет-сигналы) по второй части составляющих общей статистической модели динамики площади лесных пожаров в зависимости от времени измерения в сутках за период 1982-2011 гг. как продолжение физико-математического анализа массива статистических данных 
Кроме того, повышается также точность инерционного прогнозирования лесных пожаров, в её программной части - это специальное программное обеспечение, с помощью которого заказчик осуществляет мониторинг лесов в режиме реального времени с момента регистрации первого на данной территории лесного пожара и определяет количество возгораний на одной и той же координате.

В итоге появляется практическая возможность, с использованием многолетних данных о лесных пожарах на территории, экологического и технологического (пожаротушения) мониторинга для прогнозирования.

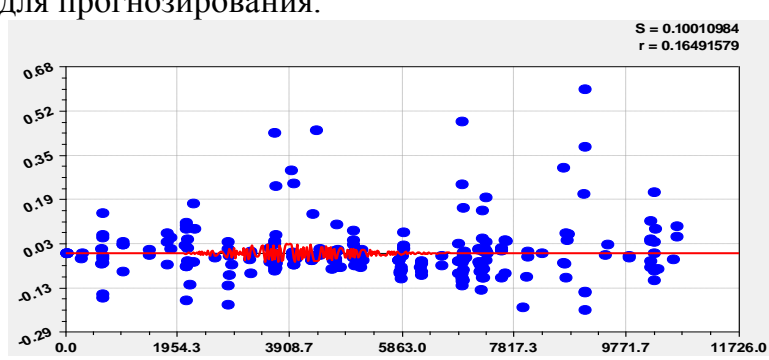

Рис. 5. Графики отдельных волновых уравнений по второй части составляющих общей статистической модели динамики площади лесных пожаров в зависимости от времени измерения в сутках за период 1982-2011 гг. как 20-е колебательное возмущение в виде асимметричного вейвлет-сигнала

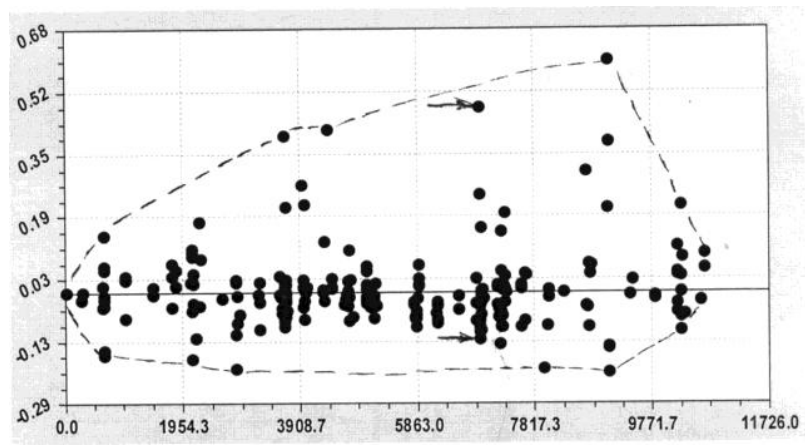

Рис. 6. Остатки после 20-го колебания в виде шума, который появляется из-за возникновения пары противоположно расположенных относительно оси абсцисс двух точек (показаны стрелками $t=6922$ суток $S=0.475544$ га и $t=6922$ суток $S=-0.119456$ га), а пунктирной линией показана динамика интервала разброса остатков

Одновременно происходит уточнение распределения времени слежения у аппаратной части системы на те или иные объекты по выявленным статистическим моделированием закономерностям, а также прогнозный расчет по ним значений параметров будущих лесных пожаров.

\section{Параметры вейвлет-сигналов динамики площади лесных пожаров, га}

Таблица 6

\begin{tabular}{|c|c|c|c|c|c|c|c|c|c|}
\hline \multirow{2}{*}{$\begin{array}{c}\text { № } \\
i\end{array}$} & \multicolumn{4}{|c|}{ Амплитуда колебания (3) } & \multicolumn{4}{|c|}{ Полупериод и сдвиг колебания (3) } & \multirow{2}{*}{$\begin{array}{l}\text { Коэфф. } \\
\text { коррел. }\end{array}$} \\
\hline & $a_{1 i}$ & $a_{2 i}$ & $a_{3 i}$ & $a_{4 i}$ & $a_{5 i}$ & $a_{6 i}$ & $a_{7 i}$ & $a_{8 i}$ & \\
\hline 1 & 0,099469 & 0 & $1,10516 \mathrm{e}-6$ & 1,12425 & 0 & 0 & 0 & 0 & \multirow{5}{*}{0,7050} \\
\hline 2 & $-3,53087 \mathrm{e}-20$ & 5,60399 & 0,0011208 & 1,00071 & 0 & 0 & 0 & 0 & \\
\hline 3 & $-4,14493$ & 0 & 0,0018387 & 1 & 3638.952 & $-0,68395$ & 1 & $-1,39525$ & \\
\hline 4 & 1,69642 & 0 & 0,0012152 & 1 & 44,11963 & 0 & 0 & 0,78600 & \\
\hline 5 & $-5,41258 \mathrm{e}-5$ & 3,76958 & 1,72078 & 0,33592 & 40,15229 & 0 & 0 & 0 & \\
\hline 6 & $-4,89109 \mathrm{e}-20$ & 7,07555 & 0,0038303 & 1,05028 & 5,09452 & 0 & 0 & 1,80841 & 0,3577 \\
\hline 7 & $8,13875 \mathrm{e}-20$ & 6,88600 & 0,0048578 & 1 & 8,99494 & $5,66406 \mathrm{e}-11$ & 1 & 0,36339 & 0,3643 \\
\hline 8 & $1,11073 \mathrm{e}-22$ & 8,07420 & 0,0062925 & 1 & 5,95468 & $-1,48025 \mathrm{e}-6$ & 1 & 4,07923 & 0,3432 \\
\hline 9 & $-8,31051 \mathrm{e}-20$ & 6,98146 & 0,0057093 & 1 & 4,02093 & $6,47353 \mathrm{e}-8$ & 1 & $-0,021803$ & 0,2504 \\
\hline 10 & $6,86038 \mathrm{e}-8$ & 2,93353 & 0,082222 & 0,60889 & 4,31117 & 0 & 0 & 0,90254 & 0,2176 \\
\hline 11 & $-0,0061436$ & 0 & $-0,00027068$ & 1 & 59,70359 & $-7,49475 e-9$ & 1 & 1,83074 & 0,2247 \\
\hline 12 & $-1,75252 \mathrm{e}-5$ & 1,50472 & 0,0015981 & 1 & 3,01407 & $6,09900 \mathrm{e}-10$ & 1 & 3,21235 & 0,1968 \\
\hline 13 & 0,00088503 & 0 & $-0,00048654$ & 1,00082 & 454,9201 & 0,0019775 & 0,99997 & 3,09600 & 0,1797 \\
\hline 14 & $1,72624 \mathrm{e}-12$ & 4,18325 & 0,0037123 & 1 & 7,92140 & 0 & 0 & 1,95500 & 0,2077 \\
\hline 15 & $-8,09530 \mathrm{e}-83$ & 23,07698 & 0,0026183 & 1 & 1,50027 & 0 & 0 & $-3,40294$ & 0,2233 \\
\hline 16 & $7,58860 \mathrm{e}-5$ & 0,68221 & $6,02516 \mathrm{e}-7$ & 1 & 13,99570 & 0 & 0 & 0 & 0,1559 \\
\hline 17 & $3,33572 \mathrm{e}-26$ & 10,12949 & 0,012306 & 1,01046 & 3,31899 & 0 & 0 & $-4,08812$ & 0,2361 \\
\hline 18 & $6,35400 \mathrm{e}-16$ & 4,99166 & 0,0027039 & 1,00677 & 1,00957 & 0 & 0 & $-3,98463$ & 0,1285 \\
\hline 19 & $-0,060688$ & 1,22372 & 0,023509 & 1 & 56,13935 & 0,075774 & 1 & $-0,0027380$ & 0,2346 \\
\hline 20 & $-9,60783 e-20$ & 7,74883 & 0,013405 & 1 & 1,40310 & $5,78986 \mathrm{e}-9$ & 1 & $-0,82540$ & 0,1213 \\
\hline 21 & $-1,24998 \mathrm{e}-60$ & 20,98269 & 0,0099236 & 1,02126 & 1,49818 & 0 & 0 & 3,62390 & 0,2972 \\
\hline 22 & $1,33889 \mathrm{e}-55$ & 16,96104 & 0,0044297 & 1 & 1,49781 & $-9,24608 \mathrm{e}-5$ & 1 & $-4,72867$ & 0,1649 \\
\hline
\end{tabular}


Библиографический список

1. Мазуркин, П.М. Идентификация статистических устойчивых закономерностей / П.М. Мазуркин // Наука и мир: международный научный журнал. - 2013. - N 3(3). - С.28-33.

2. Мазуркин, П.М. Решение 23-ой проблемы Гильберта Междисциплинарные исследования в области математического моделирования и информатики. Матер. 3-й научно-прак. internetконф. / П.М. Мазуркин. - Ульяновск: SIMJET, 2014. - С. 269-277.

3. Мазуркин, П.М., Блинова, К.С. Активность Солнца и годичная динамика лесных пожаров на особо охраняемой территории / П.М. Мазуркин, К.С. Блинова // Успехи современного естествознания. - 2013. - № 1. - С. 102-107.

4. Мазуркин, П.М. Асимметричные вейвлет-сигналь многолетней динамики численности лесных пожаров Республики Марий Эл / П.М. Мазуркин, К.С. Блинова, А.В. Хазиев // Вестник Казанского технол. ун-та. - 2013. - Т. 16. - № 15. - С.148-151.

5. Мазуркин, П.М. Каткова, Т.Е. Моделирование многолетней динамики изменения площади лесных пожаров / П.М Мазуркин, Т.Е. Каткова // Вестник Воронежского института ГПС МЧС России. -2013. - № 1 (6). - С.31-37.

6. Мазуркин, П.М., Каткова, Т.Е. Анализ многолетней динамики удельной площади лесных пожаров / П.М. Мазуркин, Т.Е. Каткова // Вестник Воронежского института ГПС МЧС России. - 2013. - N 2 (7). - С.37-43.

7. Мазуркин, П.М., Каткова, Т.Е. Вейвлет-анализ многолетней динамики локальной численности лесных пожаров / П.М. Мазуркин, Т.Е. Каткова // Современные проблемы науки и образования. - 2013. - № 5 - [Электронный ресурс] URL: http://www.science-education.ru/111-10164 (дата обращения: 26.09.2013)

8. Мазуркин, П.М., Скорикова, Л.А. Динамика температуры горения древесных опилок при испытании сжиганием П.М. Мазуркин, Л.А. Скориков // Вестник КНИТУ. - 2011. - № 7. - C.58-61.

9. Мазуркин, П.М., Филонов, А.С. Математическое моделирование. Идентификация однофакторных статистических закономерностей: учеб. пособие / П.М. Мазуркин, А.С. Филонов. - Йошкар-Ола: МарГТУ, 2006. - 292 с.

10. Пат. 2406079 Российская Федерация. МПК G 01 № 25/00. G 01 № 33/46 (2006.01). Способ испытания древесных материалов по температуре сгорания / Мазуркин П.М.. Кудрявцева Л.А. (РФ); заявитель и патентообладатель Марийский гос. тех. ун-т. - № 2009133872/28; заявл. 09.09.2009; опубл. 10.12.2010.

11. Пат. 2449272 Российская Федерация. МПК G 01 № 33/46. А 01 G 23/00 (2006.01). Способ испытания древесных материалов на горючесть / Мазуркин П.М. Кудрявцева Л.А.; заявитель и патентообладатель Марийский гос. тех. университет. - № 2009133878/15; заявл. 09.09.2009; опубл. 27.04.2012; Бюл. №12.

12. Пат. 2416793 Российская Федерация. МПК G 01 № 33/46. А 62 С 3/02 (2006.01). Способ испытания лесных горючих материалов на воспламеняемость / Мазуркин П.М.. Кудрявцева Л.А.. Егорова Е.А. (РФ); заявитель и патентообладатель Марийский гос. тех. ун-т. - № 2009133875/12; заявл. 09.09.2009; опубл. 20.04.2011.

\section{ANALISIS OF FOREST FIRES PERENNIAL STATISTICS}

Mazurkin P.M.

Volga State University of Technology; Ioshkar-Ola, Russia

Time scale of registration of forest fires in the past measure in days, and for zero value of time of registration take the moment of the first account of forest fire registered in the book. From the book of the account accept primary indicators about forest fires, carry out updating of statistical data of rather accepted time scale of registration of forest fires, in addition consider derivatives from primary indicators. Statistical models of indicator everyone primary and derivative of it depending on time of registration of forest fires are given. The method of identification of wave functions in the form of asymmetric wavelet signals is stated briefly.

Keywords: forest fires, indicators, measurement, dynamics, regularities, wavelet signals. 